\title{
Interview with John Horton Conway
}

Dierk Schleicher

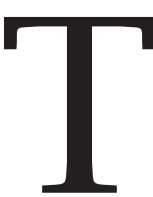

his is an edited version of an interview with John Horton Conway conducted in July 2011 at the first International Mathematical Summer School for Students at Jacobs University, Bremen, Germany, and slightly extended afterwards. The interviewer, Dierk Schleicher, professor of mathematics at Jacobs University, served on the organizing committee and the scientific committee for the summer school. The second summer school took place in August 2012 at the École Normale Supérieure de Lyon, France, and the next one is planned for July 2013, again at Jacobs University. Further information about the summer school is available at http://www.math.jacobs-university.de/ summerschool.

John H. Conway is one of the preeminent theorists in the study of finite groups and one of the world's foremost knot theorists. He has written or co-written more than ten books and more than onehundred thirty journal articles on a wide variety of mathematical subjects. He has done important work in number theory, game theory, coding theory, tiling, and the creation of new number systems, including the "surreal numbers". He is also widely known as the inventor of the "Game of Life", a computer simulation of simple cellular "life" governed by simple rules that give rise to complex behavior. Born in 1937, Conway received his Ph.D. in 1967 from Cambridge University under the direction of Harold Davenport. Conway was on the faculty at Cambridge until moving in 1986 to Princeton University, where he is the von Neumann Professor. He is a fellow of the Royal Society of London and has

Dierk Schleicher is professor of mathematics at Jacobs University in Bremen, Germany. His email address is dierk@ jacobs-university. de.

We would like to thank Joris Dolderer and Zymantas Darbenas for their contributions to this interview and Alexandru Mihai for some of the pictures.

DOI: http://dx.doi.org/10.1090/noti983

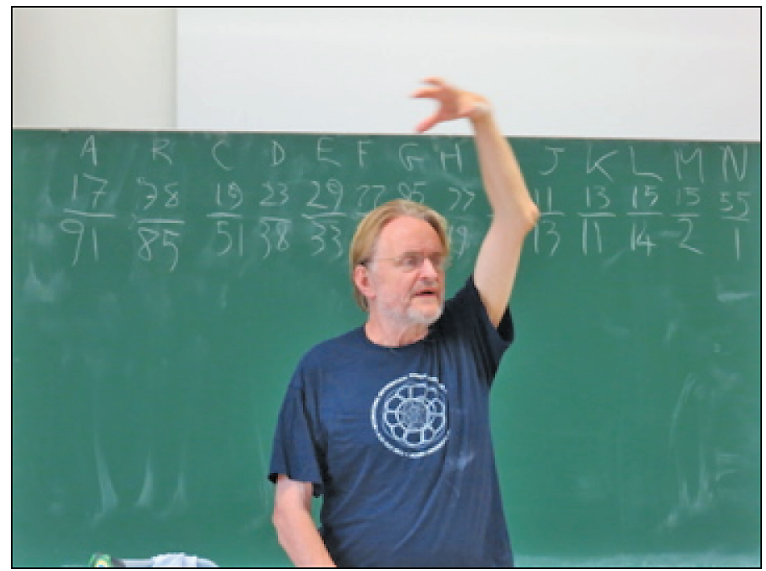

John Horton Conway in August 2012 lecturing on FRACTRAN at Jacobs University Bremen.

received the Pólya Prize of the London Mathematical Society and the Frederic Esser Nemmers Prize in Mathematics of Northwestern University.

Schleicher: John Conway, welcome to the International Mathematical Summer School for Students here at Jacobs University in Bremen. Why did you accept the invitation to participate?

Conway: I like teaching, and I like talking to young people, and I expected to enjoy myself. I used to say about myself that if it sits down, I teach it; if it stands up, I will continue to teach it; but if it runs away, I maybe won't be able to catch up. But now it only needs to walk away and I won't be able to catch up, because I had a stroke a short time ago. Schleicher: Has that ever happened to you that people have run away from you in your teaching? Conway: Yes, after five or six hours being taught something, people edge away. You know, British students aren't so disciplined as German ones.

Schleicher: At this summer school, there are students from twenty-five different countries, with different levels of politeness, and they have not edged 
away, quite the opposite. You are a professor in Princeton, and people come to Princeton to study with people like you...

Conway: Yes, to some extent.

Schleicher: ... and now you come here to the students. Of course, the students we have here are even younger than most undergraduates in Princeton. Is it different for you to teach the summer school students?

Conway: I never treat anybody any differently, roughly speaking. I teach graduate courses in Princeton, and I teach undergraduate courses. I come to places like this and other similar events in the States. I never really change my style of teaching. I don't change the topics I teach very much. If a student is a younger person, I don't go into so many details, but it is the same stuff for me. I am a very elementary mathematician, in a sense.

Schleicher: Then you are a very deep elementary mathematician.

Conway: I will accept your compliment, if that is what it was meant to be, but...

Schleicher: Yes, it was.

Conway: ... How might I say this? It's harder to take easy, baby-type arguments and to find something new in them than it is to find something new in arguments at the forefront of mathematical development. All the easy things at first sight appear to have been said already, but you can find that they haven't been said.

Schleicher: That puzzles me a bit, because you are one of the people at the forefront of mathematicsperhaps at the forefront of unexpected mathematics.

Conway: I think the last clause I can accept. But it is my own mathematics. I discovered the surreal numbers, which are absolutely astonishing. The definitions are absolutely trivial. Nobody had thought about them before, nobody was trying. In mathematics, there are worthwhile subjects. Very famous and deep mathematicians have investigated them, and it's very hard to find anything new. Most of my colleagues at Princeton make one topic their own and become world experts on it. I don't do that. I am just interested in a lot of things. I don't get very deeply into any of them. I get moderately deep.

Schleicher: I take this more as an indication of your modesty.

Conway: Here is another thing I say about myself: I am too modest. If I weren't so modest, I'd be perfect. I am working on the modesty.

Schleicher: Good luck with that work! Speaking of your modesty, what do you think...

Conway: I don't think I am modest at all, but carry on.

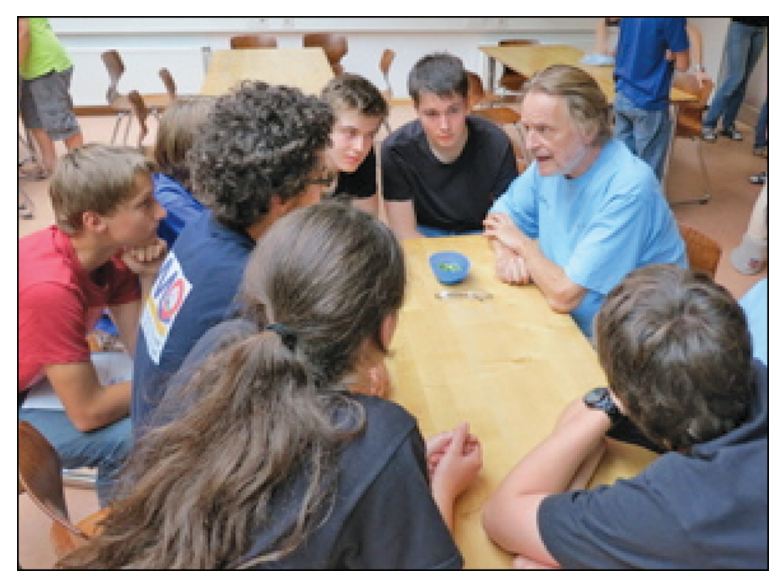

Students are clearly not edging away.

Schleicher: Let me ask the question anyway. What do you consider your greatest idea, your greatest achievement?

Conway: I don't know. I am proud of lots of things, and I don't think there is one thing I consider my greatest achievement. My colleagues would probably say the work on group theory. I don't consider that to be my greatest achievement. I think it's pretty good, but that's about it. I am glad they value it, so it means that in their eyes I am not regarded as totally frivolous. In my eyes, I am totally frivolous. But I have two particular things I can mention. One is fairly recent, the Free Will Theorem, and the other, rather less recent, is the surreal numbers. I value them, or estimate them, in different ways: with the surreal numbers I discovered an enormous new world of numbers. Vastly many numbers, inconceivable. Nobody else has discovered more numbers than I have. In a sense, it beats so-called conservative mathematicians at their own game, because it produces a simpler theory of real numbers than the traditional theory, which has been on the books for nearly two hundred years now. So I am very proud of that and astonished I was so lucky to find it.

\section{Free Will Theorem}

The other more recent work is the Free Will Theorem, which I found jointly with a colleague of mine, Simon Kochen; I would certainly have never found it by myself. It says something at a provable level about the notion of free will, which philosophers have been arguing about for ages, two thousand years at least. It wasn't something everybody wanted to know, but it's proved at the mathematical level of certainty-very nearly, anyway. Personally, I am proud of it because I have never thought about anything like that before. I've read philosophy books, but I've never imagined 


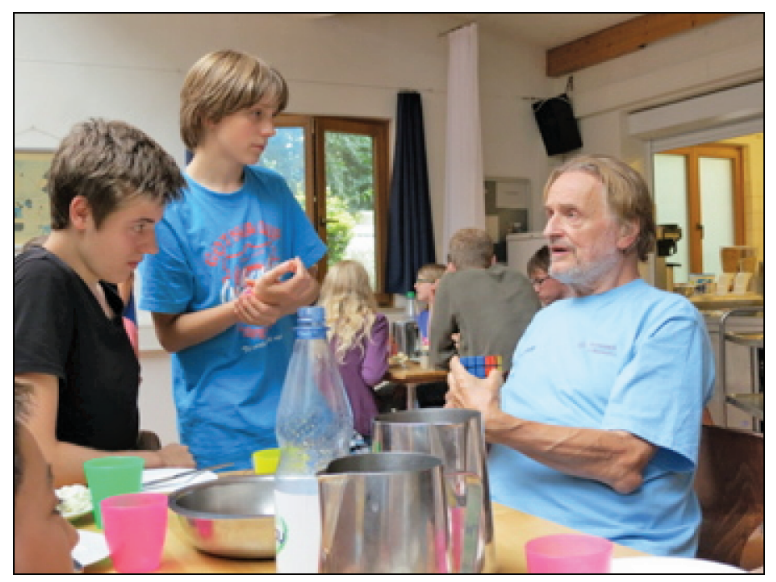

Mathematical toys and games, such as the Rubik's Cube, are always an exciting topic of mutual interest for Conway and his audience.

making any progress. In general you don't make progress on philosophical problems. Instead of tackling the problem as everybody else did, I was thinking about something else, thinking about physics, and, whoosh-something about free will could be said.

Schleicher: So could it be that this or other discoveries of yours were shaped by coincidence or by luck?

Conway: Partly luck. I would have never done anything without my colleague. He taught me a lot of quantum mechanics. When I was at the university in England, I took courses in quantum mechanics, including one from Dirac, the great quantum mechanic! A wonderful physicist and a shy man. I understood nothing. That was strange, but there is a famous saying by Feynman that if you meet somebody who tells you they understand quantum mechanics, then you have met a liar, and not a good liar at that. So I don't claim to understand quantum mechanics. My friend Simon Kochen taught me one thing about quantum mechanics which I understood, and I find that many physicists don't understand that one thing (of course, they understand many things that I don't). And that one thing we were able to pursue until we had this great theorem. If we make reasonable assumptions, including the assumption of free will, this one thing tells us that the little elementary particles are doing their own thing all over the universe. One atom is deciding to move a little bit leftwards and another to move a little bit rightwards. And it all very nearly cancels out, but not quite. And here [points to Schleicher] is what we call a life. You might be a robot, but I doubt it. I rather suspect you to have the same kind of consciousness as I have. And that is probably a manifestation of the freedom of the particles inside you: they do their own thing.
Schleicher: Could you make a simple statement about what exactly, or intuitively, the Free Will Theorem says?

Conway: Yes. [Throws a piece of paper.] I just decided to throw that piece of paper on the floor. I don't believe that that was determined at the start of the big bang, 14 billion years ago. I think it's ludicrous to imagine that the entire development of the universe, including, say, this interview, was predetermined. For the Free Will Theorem, I assume that some of my actions are not given by predetermined functions of the past history of the universe. A rather big assumption to make, but most of us clearly make it. Now, what Simon and I proved is, if that is indeed true, then the same is true for elementary particles: some of their actions are not predetermined by the entire past history of the universe. That is a rather remarkable thing.

Newton's theory was deterministic. In the 1920s, Einstein had difficulties believing that quantum mechanics was not deterministic. That was regarded as a defect of quantum mechanics. Certainly when I tried to learn quantum mechanics and didn't succeed, I thought it was a defect. It's not a defect. If the theory could predict what one of those particles could do, then that theory would be wrong, because, according to the Free Will Theorem-supposing we do have free will-a particle doesn't make up its mind what it's going to do until it does it or until shortly before it does it.

Let me describe the theorem this way. Suppose there is only a very tiny amount of free will in humans: you can press either button A or button $\mathrm{B}$ in a manner that is not predetermined. That is a very tiny part of what we normally consider free will for humans. And if we have that tiny amount of free will, so do the elementary particles, in a sense that a particle in response to some experiment can choose which path, C or D, that it follows. It has free action. It chooses $\mathrm{C}$ or $\mathrm{D}$ in a manner that is not a predetermined function of all the information in the past history of the universe.

Schleicher: You believe that humans have free will. Conway: I do. Strict determinism tells us that all of our actions are predetermined by the past history of the universe. I don't know, maybe it is. I can't disprove it. I can prove that I can't disprove it. I can prove that you [points to Schleicher] can't disprove it either. But I believe anyway that humans have free will.

Schleicher: That is your belief.

Conway: And it is very strong. If you or somebody else doesn't believe this, I am not going to argue with you, because I know that I can't disprove the determinist's position. After giving lectures on this subject in various places, sometimes I have asked whether there were any determinists in the audience. Usually in an audience of a 
hundred, twenty people put their hands up. They are usually among the most intelligent members of the audience, because it takes some intelligence to disbelieve something that everybody else feels is obvious or to believe something that everybody else feels is ludicrous. Several times people have come up to me and told me they were determinists and expected me to argue the matter. But since I've proved that nobody can disprove determinism, what is the point in trying to disprove determinism? I have no argument with determinists or, I should have said, I have no arguments with determinists. Schleicher: The usual interpretation of quantum mechanics is that the behavior of the elementary particles is simply random.

Conway: You know, randomness doesn't help. If the action of each particle were a predetermined function of its past plus a random string of bits, then we might as well suppose that this string of bits was produced just before the universe was created, and this is excluded just as well as totally deterministic behavior.

\section{Cellular Automata}

Schleicher: One achievement of yours that you didn't mention is one that you are perhaps best known for, the invention of the Game of Life, the theory of cellular automata.

Conway: Yes, that is true. And sometimes I wish I hadn't invented that game.

Schleicher: Why?

Conway: Well, because I am pretty egotistical. When I see a new mathematical book for a general audience, I turn to the index, I look for a certain name in the back, and if I see this name, it shines out at me somehow. And it says, page 157, pages 293-298, or whatever. So I eagerly turn to those pages, hoping to see some mention of my discoveries. I only ever see the Game of Life. I am not ashamed of it; it was a good game. It said things that needed to be said. But I've discovered so many more things, and that was, from a certain point of view, rather trite-to me anyway. It is a bit upsetting to be known for this thing that I consider in a way rather trivial. There are lots of other things to be discovered about surreal numbers. And the Free Will Theorem is recent, and therefore I am still flushed with enthusiasm about it.

Schleicher: I understand what you are saying. But is it possible that the Game of Life has perhaps not been fully developed or understood? Maybe there is a theory waiting to be discovered?

Conway: No, it's been overdeveloped. You won't interest me in the Game of Life.

Schleicher: But Steven Wolfram is very interested in cellular automata. Doesn't he think it is the future of everything?

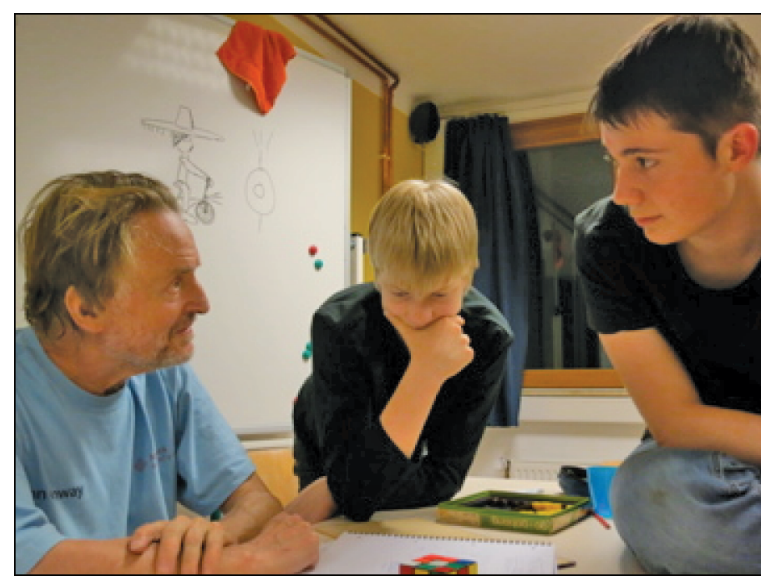

John Conway likes to challenge people in a game of "dots and boxes"-that game is often played in high schools but has surprisingly deep mathematical content

Conway: I think he is wrong. And I am rather astonished that he has the opinions that he has, because he supposedly studied physics. I shouldn't say "supposedly"-pardon me. He should be aware of the fact that the universe behaves in a manner that-at least most competent physicists believeis not deterministic. And cellular automata are things that, like the life game, are deterministic. So in my opinion, it's provable that the universe is not a cellular automaton.

Schleicher: I am a bit surprised to hear you say that one should believe what the majority of scientists in a particular field say. Have you ever cared about the opinion of the majority?

Conway: No, not very much. But physics is not my profession. And I suppose I just try to bolster this opinion by saying it's not only me. I'm surprised Wolfram believes that the universe is a cellular automaton. I met him a long time ago, and he was very friendly. He was chiefly interested in the Game of Life. I remember walking with him and a friend of his when we both attended a conference near Marseilles. We used to walk down to the Mediterranean along the nice rocky path and then come back the same way after spending an hour at the beach, talking all the time about-well, largely about things like cellular automata, but also about philosophy and other things. I didn't see him for a long time, and then we had a discussion that wasn't entirely amicable about ten years ago. I met him again last year or the year before at the celebration of the life of Martin Gardner, and we fell back into our old habit of having interesting intellectual conversations. It's rather funny, because he made his millions by starting a company and doing a good thing. This man could give me one or two million dollars without noticing. 


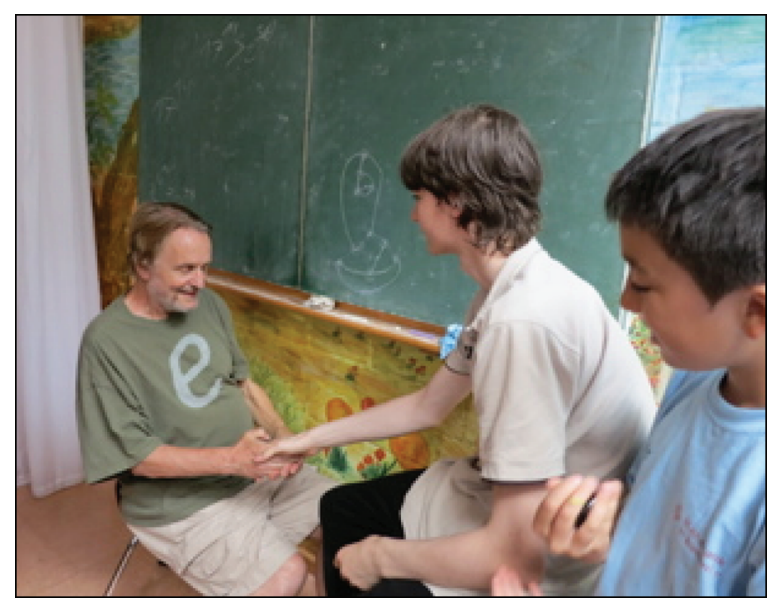

Conway is always ready for any kind of mathematical game.

I don't think that Wolfram's theories are tenable. His book is very interesting, but as the explanation of the universe-I don't think he's got the right idea, possibly because he doesn't understand the one thing of quantum mechanics that I do. Lots of physicists don't understand this. I won't claim any special virtue in understanding it. It took me ten years to do so by talking with my friend Simon Kochen for several hours a day, except Saturdays and Sundays, talking about quantum mechanics, trying to understand it. Really, we didn't know what we were talking about. We were talking about particular problems at various times. But in retrospect, perhaps I should say, it was predetermined that we would go to the Free Will Theorem! But of course it wasn't predetermined. I don't believe anything is predetermined, roughly speaking. Things concerning large inanimate objects are predetermined. This tree is not going to start walking around the lawn. The building, I hope, is not going to fall down. Physical laws, as regards inanimate objects, have a high degree of predetermination. But as regards animate objects, such as people walking around on the lawn and a dog that might accompany them, that doesn't look predetermined to me. I can't prove that it isn't. And nobody else can.

\section{Inventing the Game of Life}

Schleicher: What made you invent the Game of Life, and how did it happen?

Conway: I was telling you of my Jugendtraum, my youth dream, that undecidable complexity is not as far out as one might expect but might happen just around the corner. There was a book called Automata Studies, one of those orange Princeton books, that gave me quite a lot of topics to think about. One of them was a mention of von Neumann's cellular automaton, which was a universal computing device in the sense that it could emulate any other computer. This was a very complicated thing, with twenty-nine states and a neighborhood of five cells, and it had a very long list of transition rules that would be virtually impossible to check. Von Neumann had designed this thing carefully so as to have this universality property. I thought you didn't have to design it, because it would happen almost automatically, given a sufficient amount of complexity.

One metaphor that has been with me for a long time is the following: I like to think of a huge abandoned warehouse equipped with logical devices such as AND, OR, and NOT gates. Suppose a maniac lived there who would solder together a big number of these devices just randomly. Then with enough time you could learn how to program this, and it wouldn't take a lot of intelligent design so that the big circuit would be unpredictable and probably even universal. This idea also underlies my recent paper on amusical permutations, which I wrote for the American Mathematical Monthly special issue that you invited me to contribute to.

It happens on several occasions that people have proved something like universality assertions, and then people start to think that that proof is an estimate of how complicated a universal device has to be. Let me give you a number of examples. Gödel proved his famous incompleteness theorem by inventing things called "Gödel numbers" for propositions and then talking about the statement with Gödel number $n$ and evaluating this for the parameter equal to $n$ and so on. The books used to say that the Gödel number of any statement of any interest must be enormously big, but I didn't see why these had to be so big. Similarly, it is often said that a universal Turing machine has to be terribly complicated, but I didn't see why that had to be so. You see, von Neumann's universal cellular automaton had twenty-nine states and very complicated transition rules, and I didn't think that was necessary, so I tried to find a much simpler automaton that was universal too.

The Game of Life was, I think, my first foray into the field-well, I'm not quite certain whether it was really the first. I guessed it would be universal.

Schleicher: And how did you discover it?

Conway: I tried out dozens and dozens of different automata, not necessarily to see whether they were universal, because that is rather difficult to work out. I tried to design rules that were unpredictable in behavior but that I could study for long enough to learn how to program them. If you are shown into the warehouse that I mentioned and had only one day, you wouldn't learn how to program it [the big circuit]. In the case of the life game, I studied this with a little community of graduate students. We studied different sets of rules, played 
them on Go boards over what I think was eighteen months-not all the time, but every now and then during coffee breaks. We eventually found this wonderful system that appeared to be universal. The day when we thought it would be successful I very much remember. Richard Guy was staying in Cambridge, which he didn't often do. He was given the job of blinker-watcher, as he is a very precise sort of person. Blinkers are three sets of aligned cells that alternate in period 2 .

Schleicher: I know the Game of Life well: when I was in high school, this was a hot topic among all the math folks there, and it was the first computer program I ever wrote in binary machine code on my first computer.

Conway: We did this all by hand on Go boards with blinkers, and other small objects-you don't have to update them in every generation. You just have to keep a note on whether it's an even or odd generation. Only when the rest of the game is getting near it do you bother to update it. To keep track of these small objects is the job of the blinker-watcher. At one point, he said, "Come over here! My bit is walking!" And indeed it was. That was the discovery of the glider. In the Winning Ways book there is a little piece on gliders, and it says, "Some guy said 'my bit is walking',", and this "guy" was Richard Guy. We had thought of things like "spaceships" when trying out all sorts of rules. This was the first time that a spaceship actually happened: five cells at any given time, and they appeared naturally. Of course we discussed this, because we had hoped our cellular automaton would be universal and in order to have a computer in which, instead of wires and pulses of electricity, you had paths on which gliders (or something) were actually traveling. As soon as we discovered them we set about having them crash; there are about forty different ways of crashing them. That led eventually to the proof of universality.

I offered a prize for anyone who could come up with a Life configuration whose population grew indefinitely. That aim was purposely stated rather widely. What I had wanted was what it eventually became-something that would emit gliders regularly-but I thought anything that just showed that the typical configuration didn't just die off or settle down would be interesting. Later on, people found “3-4 Life”. I don't remember the details. Here the population is rather large. Nobody ever proved that it is universal. More or less every system you can't understand is probably universal, but if you can't understand it, how can you prove anything about it?

The problem with Life is the problem with understanding a little bit about it and then studying it long enough to identify components that would eventually lead to universality. It's interesting that

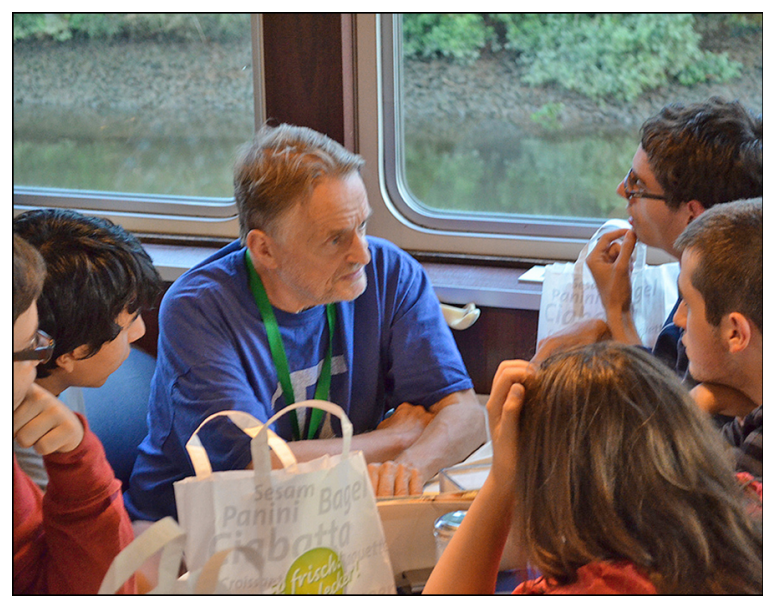

John Conway is always surrounded by students no matter where-such as here during an excursion at the summer school.

nobody else has since found a simple thing that's universal. That doesn't mean it's not there; I think it's all over the place! But it means nobody spent the roughly one year (of coffee times) that it takes to find it.

Schleicher: You just mentioned you offered cash awards. Of the awards that you offered, did you have to pay most of them, and were you ever surprised you had to pay something you didn't expect? Conway: I didn't offer cash awards all that often... Schleicher: ...you even did that to me when we met first, almost twenty-five years ago, and then played a little trick on me [both laugh].

Conway: There was this famous case, rather stupid of me. I had a little problem about whether a certain sequence tended to infinity. I was giving a lecture at Bell Labs-quite a big lecture, actually. There I proposed two forms of the problem, an easy one and a hard one. For the easy one I offered US $\$ 100$, and I said that for the hard one I would offer ten times as much, hence US $\$ 10,000 \ldots$

Schleicher: ... and that from you, the master of mental computation!

Conway: I might even have repeated this wrong number, $\$ 10,000$, afterwards. There was a person at Bell Labs, Colin Mallows, who solved the harder problem. I was quite happy and wrote him a check for $\$ 1,000$. Neil Sloane said it was $\$ 10,000$, and I didn't believe it, but it was on tape. I am not sure whether I ever listened to the tape again, I suppose I must have, and I wrote a check for $\$ 10,000$. I talked to my wife, and we decided we wouldn't buy the new car we were planning to buy; she was very good about it. Mallows got the check for $\$ 10,000$, but he said he wasn't going to accept it. I said, "You don't have to feel bad about it" and tried to persuade him a bit, but not terribly hard [smiles]. He then accepted the check for $\$ 1,000$. I think he 


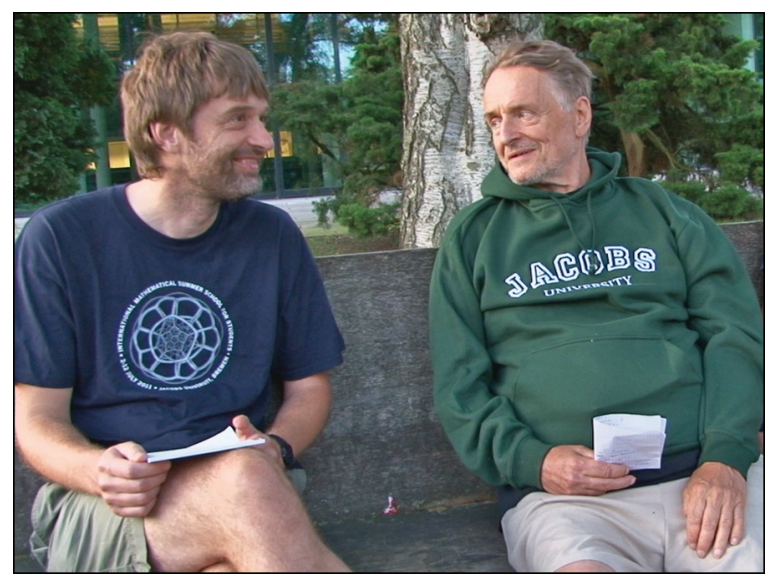

Screenshot from the interview in 2011 at the summer school. This was supposed to be a brief conversation, but developed spontaneously into a one-hour interview, interrupted only when the camera batteries died.

framed the $\$ 10,000$ check in his office but didn't cash it.

Schleicher: This is a beautiful and famous story that even made it into the New York Times!

Conway: It actually turned out he made a mistake. The first question was whether a certain sequence converged to $1 / 2$, and the second question was what the last time was when it differed from the limit by more than $1 / 20$. Much later it turned out that his answer was actually wrong. His ideas were basically right, but he had overlooked a stupid thing and I hadn't caught it, so the whole thing was replete with mistakes on all sides. Incidentally, this was not a sequence I had invented myself: it had been proposed by A. K. Dewdney, the author of a "Flatland revival" book. The sequence starts with $f(0)=0, f(1)=1$, and $f(n)=f(n-f(n-1))+f(n-f(n-2))$.

\section{Good or Bad Influence?}

Schleicher: I'd like to ask you about something different now. Some of your achievements have had a great influence on people, especially on young people, and many of them consider you a role model or a hero. How do you feel about this?

Conway: Let me say, I may have had a great influence on a lot of people, but quite often that influence has been to the bad.

Schleicher: Why is that?

Conway: I feel very guilty; I have one particular person in mind. He didn't get a Ph.D. because he became too interested in the kinds of games I was teaching him. I suspect that sort of thing has happened quite a lot, not necessarily to the extent of damaging a person's career as much as I fear I have in that case, but by making it harder for people to concentrate on the work they should be doing, because I am telling things that are more interesting. So I'm rather worried when I influence people.

Schleicher: Let me ask the question again which I asked at the very beginning. Why did you invest the time to come to the summer school to talk to young students day and night?

Conway: First of all, concerning the possibility that I might do them harm in the manner I just mentioned: I can't do much harm in one week or so. Hippocrates, the father of medicine, said, "First, do no harm." So, when I come to a summer school like this, I'm fairly sure I'm doing no harm.

Schleicher: I'm surprised that you have these worries.

Conway: I might do good. I am reminded of something. I wrote the book On Numbers and Games. Just before, I had read John Bunyan's The Pilgrim's Progress. He has a little rhyme at the front of his book. He said he showed it to various people, and some said, "John, print it"; others said, "Not so." Some said, "It might do good;" others answered, "No." This rhyme seemed so wonderful in application to my book that I quoted it at the end of the preface of On Numbers and Games. Incidentally, I was imprisoned in the same prison in which John Bunyan was imprisoned about three hundred years earlier. When I was a student I participated in a "ban the bomb" demonstration. There was a magistrate who asked everybody a few questions and then sent us to jail. I don't think it was literally the same building Bunyan had been in, but it was a pretty old building. So I have a fellow-feeling for John Bunyan. Of course, his book is called The Pilgrim's Progress, and his pilgrim is called Christian. I am not religious, certainly not so religious as John Bunyan was. So, in some sense, the book is alien to me, except that I recognize the "Slough of Despond", a phrase he used to refer to being depressed.

Schleicher: For how long?

Conway: I was very depressed in 1993. I attempted suicide. And I very nearly succeeded. That was just personal problems-my marriage was breaking down.

Schleicher: I was asking about the prison term.

Conway: That was, I think, eleven days. That's the number I remember. My memories are unreliable, as I am discovering increasingly now. I have a biographer now, Siobhan Roberts. She wrote a biography of Coxeter, the famous geometer. She asked if she could assemble a biography of me, to which I initially said no, but she persisted, and eventually I said yes. Every now and then I say something to Siobhan about something I did, and she says, "That is not consistent with the letter you wrote on July 27 th, nineteen-sixty-something, 
to Martin Gardner." That shows you what memory is like. And my role, whatever it was as I remember it, is always distinctly better than what Siobhan finds that the facts show.

Schleicher: You mentioned Martin Gardner several times. He dedicated a book to you.

Conway: Yes, I forget which book; it might be Mathematical Carnival. When Elwyn Berlekamp, Richard Guy, and I wrote the book Winning Ways, we dedicated it to Martin. I don't remember the dedication.

Schleicher: "To Martin Gardner, who brought more mathematics to more people than anyone else."

Conway: Yes, it was "to more millions than anyone else." We put in the word "millions" because Lancelot Hogben wrote a book called Mathematics for the Millions. I think that dedication is true, and it's amazing Martin Gardner did that, because he didn't understand very much mathematics. He certainly didn't do mathematics. Perhaps it's unfair to say he didn't understand. I've been rereading his book of essays. He was one of the most knowledgeable men ever, and that shines forth in his book of essays. But to his misfortune, he's still known chiefly for his "Mathematical Games" column in Scientific American, which he wrote for twenty years or more. It's more frivolous. He fell into the games column by accident: He wrote an article about hexaflexagons, which are ingenious paper toys that somebody else discovered. It wasn't his column yet; it was an article in the magazine. He died last year, several months after his ninety-fifth birthday.

Schleicher: We are very happy that we have one of the young participants, Joris, here. You have a question for Professor Conway.

Joris: Professor Conway, what did you do to get where you are now in your career?

Conway: [Laughs] I grew old. It's rather difficult to say. I am rather proud of the fact that, in some sense, I never applied for an academic position in my life. What happened: I was walking down King's Parade, the main street in Cambridge, after I received my Ph.D. The chairman of the mathematics department said, "Oh, Conway, what have you done about applying for jobs?" And I said, "Nothing." "I thought that might be the answer," he said, "Well, we have a position in our department, and I think you should apply." And I said, "How do I apply?" And he said, "You write a letter to me." And I said, "What should I put in that letter?" Then he lost his patience, pulled out of his pocket a letter-which had been written on one side-turned it over, and scribbled "Dear Professor Cassels"-that was his name-"I wish to apply for dot-dot-dot." He handed it to me, and I signed it. It would have been nice if I'd gotten the job. I didn't that year, but I got the same job the next year with the same letter.

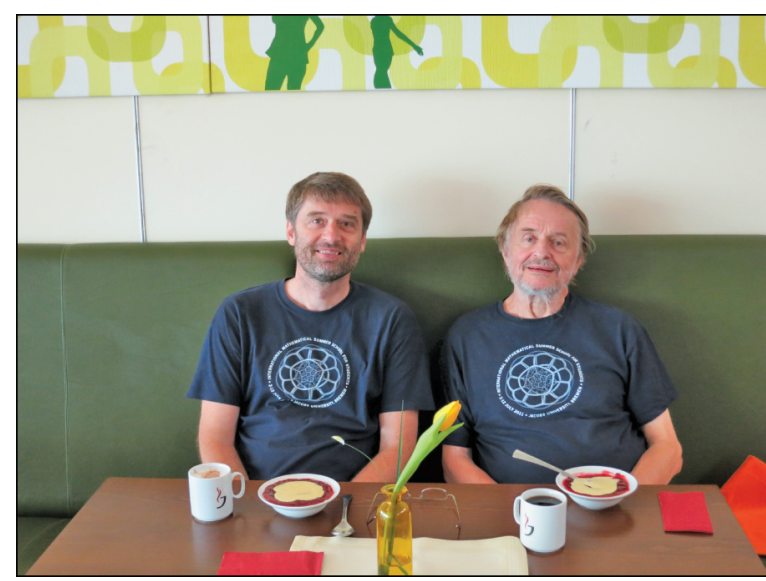

Farewell at the airport after another friendly visit: Dierk Schleicher (left) and John Conway.

\section{Keep Six Balls in the Air}

How did I do it? I don't know. I was astonishingly lucky. I literally remember my former undergraduate teacher telling my then wife that John would not be successful. She asked why. And he said, "Well, he does not do the kind of mathematics that's necessary for success." And that's true. I really didn't do any kind of mathematics. Whatever I did, I did pretty well, and people got interested in it - and that's that. I did have a recipe for success, which was always keeping six balls in the air. Now I have had a stroke, so I can't catch those balls terribly well. But what I mean is: Always be thinking about six things at once. Not at the same time exactly, but you have one problem, you don't make any progress on it, and you have another problem to change to. I had a set mix: one of the problems could be a crossword puzzle in the newspaper or something like that. Nowadays it might be a Sudoku puzzle. One of them might be a problem that would instantly make me famous if I solved it, and I don't expect to solve it, but don't give up on it; it's worth trying. There must also be one problem where you can definitely make progress just by working hard enough. Then when the guilt level rises sufficiently - and I felt guilty in Cambridge for not doing any work-you could make progress. It is sort of a routine problem that is not completely dead and might be useful. So that is my recipe for success. I don't think you asked me for a recipe for success. Maybe you did.

Joris: A little bit.

Conway: By the way, it will cost you a quarter [smiles].

\section{Enjoying Mathematics}

Schleicher: What message would you like to send to the participants of this summer school or to our future participants? 
Conway: The main component of the message is: Enjoy yourself! Of course, there is a subsidiary thing: Don't just enjoy yourself by fooling around and doing nothing. If it gets to the point where you feel that you must study something and understand it terribly deeply, and it ceases to be enjoyable-well, do something else, sleep it off, hope that it goes away, and come back again. That has been my recipe for everything. I have enjoyed myself all my life doing mathematics. I've had ups and downs in my life, but they've never been concerned with mathematics really. Mathematics has always been a sort of anodyne for me. If my life gets on top of me, then I can think about mathematics and put my personal problems aside for a moment. It's hard now. I walk with a cane, I wake up with my leg hurting, and I'm conscious every day that I'm in my seventies. I used to think I was twenty-five-I stayed twenty-five for roughly forty-five years. I don't feel twenty-five anymore as I always used to. It is very sad. Age is really catching me.

Schleicher: Yet I have to tell you that the same smile, the same inspiration, the same mathematical depth, and the impression you leave on me are the very same as twenty-five years ago when we met in Princeton. That is something that I enjoy, and I'm sure that all the students enjoy.

Conway: You are not consoling me. I still feel old. I don't feel as creative as I did a few decades ago. I'm not entirely dead; I did prove the Free Will Theorem. It's already five or six years old, and that is a good piece of creative work. And I am proud of it. But these ideas don't come as fast as they used to.

Schleicher: These theorems don't come every day, but what comes every single day here-and maybe this is a good conclusion for this interview-is that the students enjoy how accessible you are. They always are around you. We would very much like to thank you for coming here to Bremen and to this International Summer School.

Conway: I would like to thank you for inviting me-and pestering me until I actually came! I enjoy the students, talking to them, playing games with them, answering questions about mathematics when I can. And it's my life really: I tend to find young people to whom to teach something, or not necessarily teach something, but play games with them and learn from them, if necessary.

Schleicher: We are very happy that you are here. Thank you very much.

Conway: Thank you.

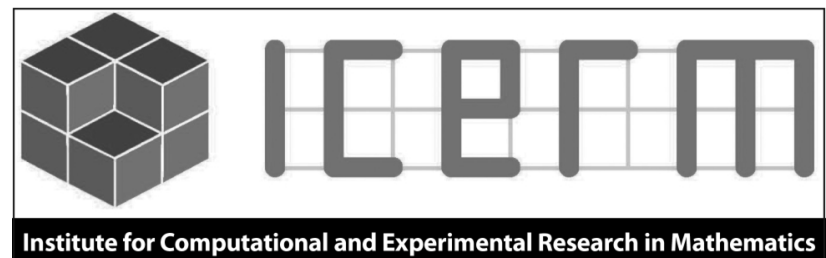

\section{Upcoming Topical Workshop}

\section{Issues in Solving the Boltzmann Equation}

for Aerospace Applications June $3-7,2013$

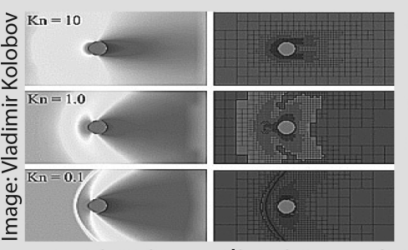

The goal of this five-day workshop is to facilitate the development of highfidelity computational capabilities for the solution of the Boltzmann equation in application to simulation of non-continuum flows. This will be accomplished by addressing the gaps in communication between mathematicians, engineers and researchers in various fields of research.

Topics of the workshop include but are not be limited to: different forms of the Boltzmann equation; reduced order models for the Boltzmann equation; mesh adaptation in velocity space; fast evaluation of the Boltzmann collision integral; simulations that account for real gas effects and chemical and electromagnetic interaction of particles; complex geometry simulations; coupling of continuum and non-continuum models; and quantification of numerical error and uncertainty of simulations.

\section{Organizing Committee:}

Alex Alekseenko, California State University, Northridge/ Air Force Research Laboratory at Wright-Patterson Air Force Base

Jose Camberos, Air Force Research Laboratory at

Wright-Patterson Air Force Base

Irene Gamba, University of Texas at Austin

Sergey Gimelshein, University of Southern California Prakash Vedula, University of Oklahoma, Norman Ingrid Wysong, Air Force Office of Scientific Research

To learn more about this and other ICERM programs, organizers, confirmed program participants, and to submit an application, please visit our website:

\section{http://icerm.brown.edu}

Participation: Applications are now being accepted. Support for local expenses may be provided. Decisions about online applications are typically made 1-3 months before the program, as space and funding permit. ICERM encourages women and members of underrepresented minorities to apply.

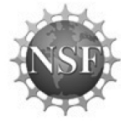

About ICERM: The Institute for Computational and Experimental Research in Mathematics is a National Science Foundation Mathematics Institute at Brown University in Providence, Rhode Island. Its mission is to broaden the relationship between mathematics and computation.

$121 \mathrm{~S}$. Main Street, 11 th Floor Providence, RI 02903 401-863-5030 info@icerm.brown.edu 